\title{
TIDAL CURRENTS IN CONSTRICTED INLETS
}

\author{
W. Douglas Baines \\ Head, Hydraulics Laboratory \\ National Research Councll of Canada, Ottawa, Ont.
}

\section{INTRODUCTION}

Many inlets along the coastline of North America are deep, wide bays which are connected to the ocean by a short channel of much smaller cross-section. Flgure l is a schematic sketch of such an inlet. It is usual in these inlets that the tide curve (water surface elevation vs. time) in the bay does not coinclde with that in the ocean. The range of varlation is discussed by Caldwell (1) in a review of inlets in the United States. In addition, Caldwell classifles this type of Inlet as one with an Inadequate entrance. This term describes well the engineering problem encountered in most of them. There are high velocitles in the entrance channel, usually near periods of slack water, which are inconvenient to navigation. In some instances these velocitles combined with local geography constitute a serlous hazard to shipping.

Typical of this class of inlet, but not so simple as the example outlined on Flg. 1, is Burrard Inlet situated on the southern mainland coast of British Columbla. Figure 2 is an outline map of this area, from which it can be seen that Burrard Inlet is three deep basins in series connected by two narrow, shallow channels. The harbour for Vancouver, Canada s major west coast port, lies along the shores of the second basin. All shlpping must pass through the First Narrows in which the currents range up to 6 knots on both ebb and flood flows. This channel is too narrow and shallow for the present day volume of shipping so plans were advanced for its enlargement. At the same time the fear was expressed that the enlargement of the First Narrows would increase the currents in the Second Narrows and thus make navigation here much more difficult than in natural conditions. As a means of studying the interaction between the two Narrows a hydraulic model was proposed. However, this would need to be very large and expensive for a reasonable accuracy to be obtained. The National Research Councll was requested to study this problem and recommend a means of solution. It was found that the mathematical model outlined below did provide a good approximation to the flow and the model proposal was dropped. In the following sections of this paper the accuracy of the mathematical model is demonstrated and the effects of the enlargement of the first Narrows are brlefly outlined.

The analysis of the flow in Burrard Inlet is general 
and should be applicable to other inlets. The author has $n$ had an opportunity to make other applications and hence is not able to state the limitations. It is hoped that throug publication of this paper that other investigations in this fleld can show the overall usefulness of this type of analy

\section{MATHEMATICAL MODEL OF THE FLOW}

Consider the simple situation shown on Figure 1 wher a bay of surface area A exists of sufficlent depth that $t$ time required for elementary waves to travel from end to en is smalier than the period of the tide. This is tantamount to assuming that the length of the bay be greater than onequarter of the tidal wave length. The discharge from the ocean into the bay will then be approximately the rate of rise in the bay water level multiplied by the surface area. Connecting the bay to the ocean there is a uniform straight channel of length $L$ and cross-section $a$, thus the mean velocity in the channel is:

$$
\mathrm{V}=\frac{\mathrm{A}}{\mathrm{a}} \frac{\mathrm{dh}}{\mathrm{dt}}
$$

where $\begin{aligned} h_{1} & =\text { water level in the bay } \\ t^{2} & =\text { time. }\end{aligned}$

Equation (1) is the equation of continuity for the system which upon integration gives

$$
\mathrm{h}_{1}=\frac{a}{\mathrm{~A}} \int_{0}^{t} \mathrm{~V} d t
$$

The only other equation required to define the flow a dynamic equation which is a simplified version of that $\mathrm{pr}$ sented by Einstein (2). The channel is as sumed to be short enough that the convective acceleration is negligible, i.e. constant discharge exists along its length at any instant. Equation (7) of Einstein (2) thus reduces to:

$$
\frac{d V}{d t}=g \frac{h_{0}-h_{1}}{L}-f \frac{V|V|}{8}
$$

where $B=$ acceleration of gravity

$\mathrm{h}_{0}=$ tide level in the ocean

$f=$ friction factor

$\mathrm{R}=$ hydraulic radius of the channel at mean tide.

As a boundary condition on Eqs. (2) and (3) the tide curve in the ocean must be specified. A cosine term is the simplest expression and has been found to be convenient to use.

$$
h_{0}=H \cos \frac{2 \pi t}{T}
$$

where

$$
\begin{aligned}
& H=\text { half range of tide } \\
& T=\text { period of tide. }
\end{aligned}
$$


CROSS-SECTION
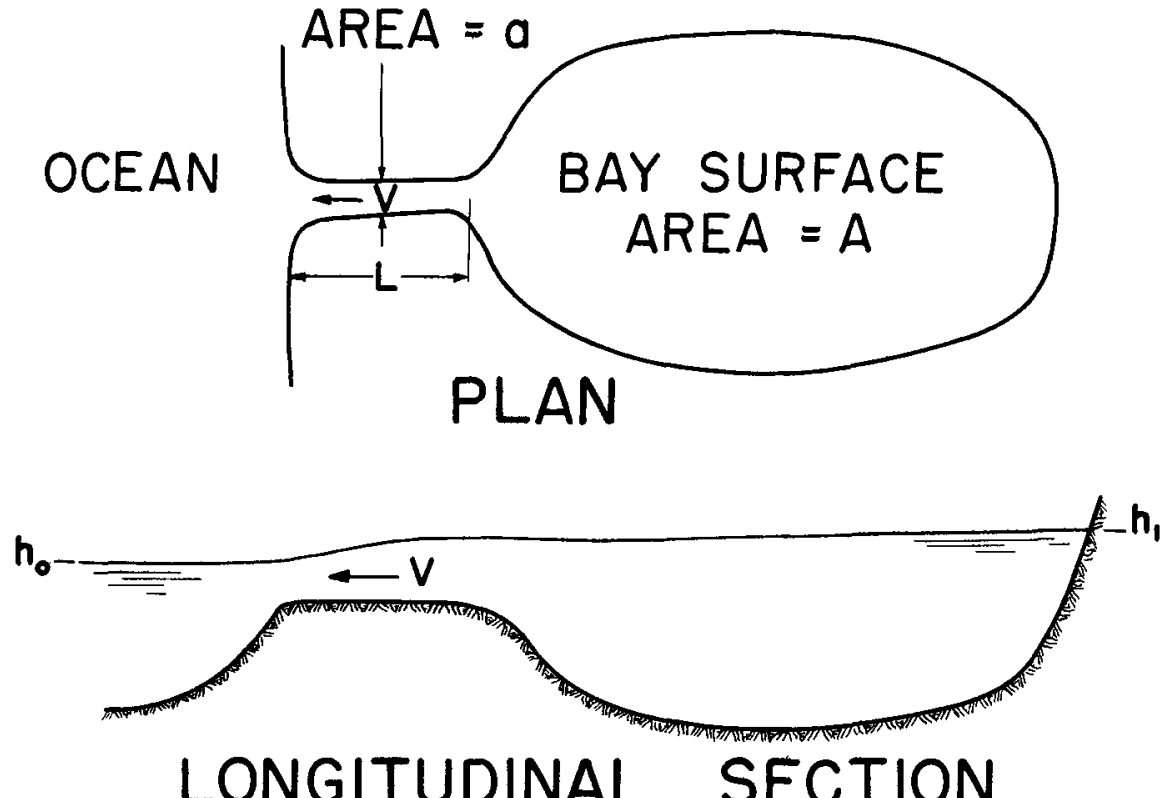

Fig. 1. Sketch of a bay with a constricted entrance channel.

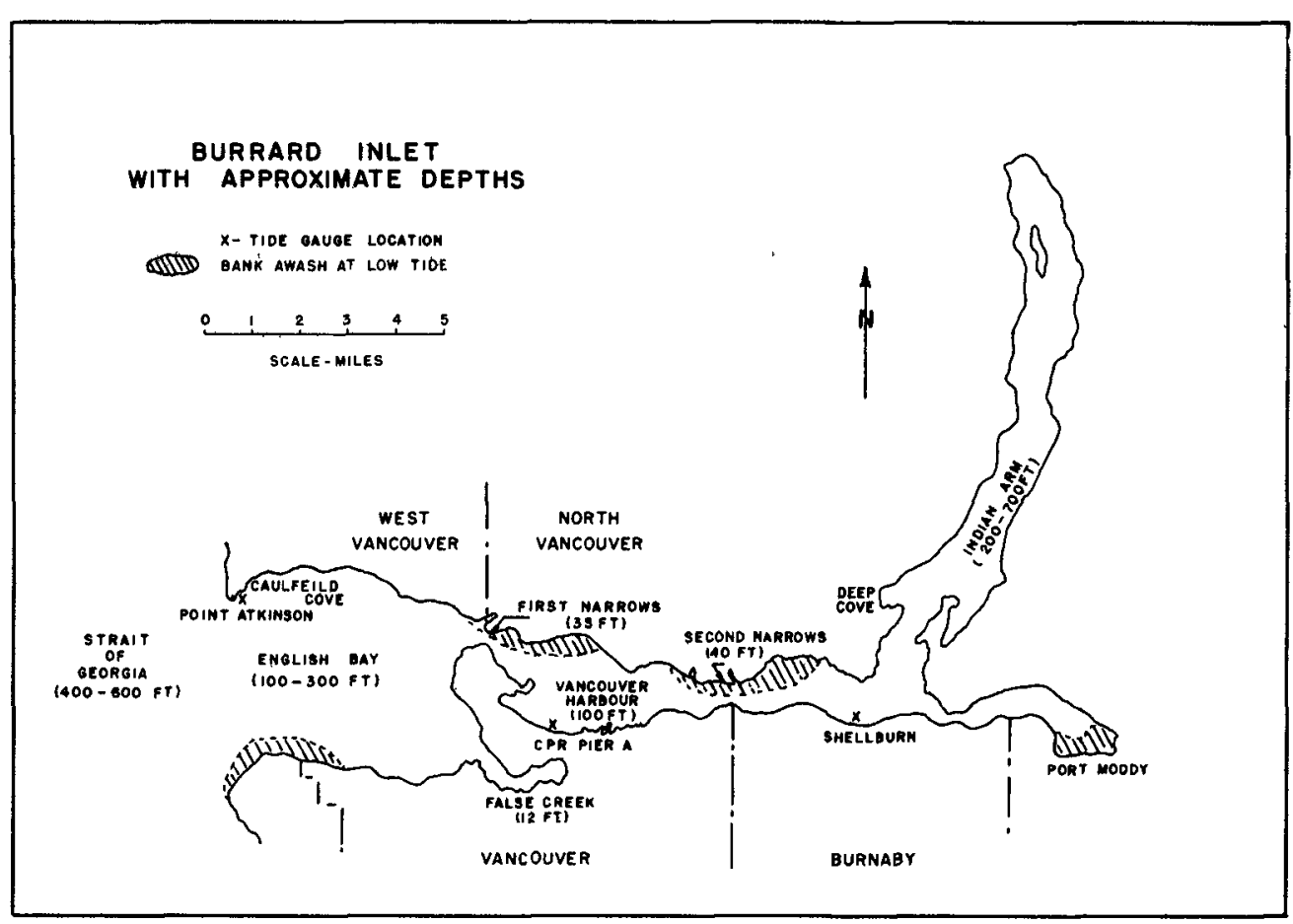

Fig. 2. Burrard inlet with approximate depths. 


\section{SIMPLIFIED SOLUTION}

It is a help in the understanding of the flow to con. sider first the simplest approximation than can be made to the above equation. If it is assumed that friction in the channel is negligible and that the change in elevation alon the length of the channel is inconsequential then Eq. (3) loses significance and Eq. (2) can be solved directly by sul stituting $h_{0}$ for $h_{l}$. The following simplified solution results.

$$
V=-\frac{2 \pi H}{T} \frac{A}{a} \sin \frac{2 \pi t}{T}
$$

Comparing Eqs. (5) and (4) shows that the current is 90 degrees out of phase with the tide. That is the maximum flood and ebb flows occur exactly at slack tide. Of course one of the assumptions was that $h_{0}=h_{1}$ and hence the tide curve in the bay has the same range and occurs at the same time as the tide in the ocean.

\section{IINEAR SOLUTION}

A combination of Eqs. (3), (4) and (5) gives the following equation for the velocity in the entrance channel:

$$
\frac{d V}{d t}=\frac{g H}{L} \cos \frac{2 \pi t}{T}-f \frac{V|V|}{8}-\frac{g a}{L A} \int_{0}^{t} V d t
$$

There is not available a method which will give an explicit solution to Eq. (6). However, if the friction term can be linearized a solution is easily obtained. This process is being widely used and Einstein discusses the consequences of such an as sumption. The absolute value of $V, 1 . \theta .|V|$ is assumed constant throughout the tide cycle, the size depend upon either the best overall accuracy desired or the part of the cycle where best accuracy is desired. Thus verificatior of the results is required if the solution is to be of great use. For the type of engineering problem under consideratis that of navigation, the maximum currents are of primary interest so the value of $|\mathrm{V}|$ is chosen such that the theory will match observed values at half tide.

The solution of equation (6) is easily obtained by th Laplace transform method (3) with the condition imposed that it must have a definite period. Were there a transient effe then the mean level in the bay would increase (or decrease) steadily. This is difficult to envision physically. It is found that the period of the current in the channel and the tide in the bay is identical to that in the ocean. Followil are the exact expressions for these quantities: 


$$
\begin{aligned}
\mathrm{V} & =-\frac{\mathrm{C}_{1}}{\mathrm{C}_{3}-1} \cos \alpha \sin \left(\frac{2 \pi \mathrm{t}}{\mathrm{T}}-\alpha\right) \\
\frac{\mathrm{h}_{1}}{\mathrm{H}} & =\frac{\mathrm{C}_{3} \cos \alpha}{\mathrm{C}_{3}-1} \cos \left(\frac{2 \pi t}{\mathrm{~T}}-\alpha\right)
\end{aligned}
$$

in which the phase shift angle $\alpha$ is defined by

$$
\tan \alpha=\frac{c_{2}}{c_{3}-1}
$$

and the following constants are used for convenience

$$
\mathrm{C}_{1}=\frac{\mathrm{Tg} \mathrm{H}}{2 \pi \mathrm{L}} \quad \mathrm{C}_{2}=\frac{\mathrm{IVIT}}{2 \pi \times 8 \mathrm{R}} \quad \mathrm{C}_{3}=\frac{\mathrm{g} \mathrm{T}^{2} \mathrm{a}}{4 \pi^{2} \mathrm{LA}}
$$

The blggest difference from the simplified solution is the phase shift defined by equation (9). It is the direct result of the inclusion of friction in the equation of motion. The tangent of the phase shift angle is proportional to the constant describing the frictional coefficients of the channel It can be seen from equations (7) and (3) that the tide lags that of the ocean by $\alpha$ and $V$ lags tide of the ocean by $\frac{\pi}{2}+\alpha$. In other words, the friction delays the tidal action by a certain amount and the current is normally $\pi / 2$ out of phase with the impressed tide.

Another unusual property of the above solution is the attenuation factor shown by equation (8). This term, which is commonly used in electrical engineering, is here used to define the ratio of the tide range in the basin to that in the ocean. Two factors influence it, the first and most readily understood is friction. In equation (8) the term $\cos \alpha$ represents the effect of friction in reducing the tide range in the basin. The greater the friction the smaller will be the basin tide. The other factor is related to the response to the basin to the impressed tide wave. The term $\mathrm{C}_{3} /\left(\mathrm{C}_{3}-1\right)$ will always be greater than 1 . In many cases $\mathrm{C}_{3}$ is much larger than 1 and the term reduces to unity. If $\mathrm{C}_{3}=1$ then resonance results and equations (7) and (8) produce infinite values. In this case the solution is no longer valid; the terms having been neglected in the basic equations would put physical limits on the current and tide level. However, for $\mathrm{C}_{3}$ not much larger than 1 the term can have values significantly greater than unity and the equations still describe the flow. In such a case the tide range in the basin will be larger than that in the ocean. Several examples of this phenomena have been given by Caldwell (1) and it appears for each case that $\mathrm{C}_{3}$ would have a value commensurate with this analysis. 


\section{COASTAL ENGINEERING}

\section{APPLICATION TO BURRARD INLET}

\section{GENERAL DESCRIPTION OF THE INLET}

As mentioned previously, the Inlet consists of three wide, deep basins the outer one of which, English Bay, is connected to the Strait of Georgia without an entrance channel. Between English Bay and Vancouver Harbour the channel is called the First Narrows. The Second Narrows cor nects the Harbour to the Upper Inlet which is forked into ti arms - Indian Arm and Port Moody. The depths of these basir and channels are indicated on Figure 2. The Narrows are the result of material being deposited in the inlet in recent geological time. This has resulted in a broad bench, dry at low tide, being formed on the north shore of each channel. The Capilano River which deposited the debris in the First Narrows has been diverted to empty directly into English Baj Iynn Creek and the Seymour River which empty into the Seconc Narrows do not carry sediment loads under ordinary conditior However, after a heavy rainfall they rise rapidly and can move everything from clay to small boulders, which is deposited in the Narrows. The shorelines between the Narrows and along Indian Arm are for a large part deposits of uncon. solidated glacial tree and alluvial deposits that form a des cover over bedrock. About half the length of the south shos consists of outcrops of sandstones, shales and conglomerate: which contribute steep slopes that are 1deal for the construction of docks. Where not exposed the rock is covered by glaclal till which also forms steep banks but is more subject to erosion.

Inspection of the tide curves in the three basins shows certain peculiarities not found in estuaries such as river mouths. The characteristics of these curves suggest immediately the usefulness of the simple derivation above. It is known for a start that the effect of the fresh water runoff is negligible. Rarely do the total discharges of al: the riversexceed one percent of the maximum flood discharge through the First Narrows. Fresh water discharge into the bay could be included in the above analysis and still retais an explicit solution. The only inconvenience is that of in. creased algebra and the difficulty of seeing the significan of the extra terms in the equation.

In the Indian Arm there is little mixing of the wate from the surface to the bottom. As a result the Upper Inle is stratified, i.e. the fresh water remains in the upper layers. Flow through the Second Narrows being highly turbulent mixes the water entering from either side and consequently Vancouver Harbour does not have such a stratification. 


\section{TIDAL CURRENTS IN CONSTRICTED INLETS}

Within any of the basins the tide curves at all stations are virtually identical (Ref. 4). However, there are appreciable differences across each of the Narrows. Note, for example, Figure 3 which presents data pertaining to the First Narrows. The tide curve at either end has the same amplitude, that is the attenuation factor is one. (Attenuation factor for a channel is defined as the ratio of curve amplitude at the landward end to that at the seaward end.) At Pier A the shape of the curve is identical to that at Caulfeild Cove except for a displacement on the time scale. In mathematical terminology this displacement is called a phase shift. Similar relationships hold for both attenuation and phase shift for the tide curves on either side of the Second Narrows (note Fig. 4). For both Narrows the phase shift appears to be nearly constant for the periods of rapid rise and fall of the water surface. During these periods the maximum flows occur. The discharge curves are roughly sinusoldal in shape but are neither the same shape nor the same phase as the tide curves. In fact the discharge curves appear to be about 90 degrees out of phase, that is, the maximum flow occurs at half tide and slack water coincides with high and low tide.

The pattern of surface currents is typical of a long, narrow inlet. This has been measured by the canadian Hydrographic Service (Ref. 5) for English Bay, First Narrows and Vancouver Harbour. The currents are all parallel to the axis of the inlet except in the widening portions where the flow is unstable. The instability combined with the geostrophic acceleration (a consequence of the earth's rotation) is probably the reason that the bulk of the flow is along the right bank in each instance. For example, Vancouver Harbour has expansions at both ends and it can be reasoned that this should cause a continuous counter-clockwise rotation to the water in the harbour throughout the tide cycle. This rotation has actually been measured (note Ref. 5). The overall current pattern thus does not appear to be influenced by the local form of the shoreline and any changes to it should be predictable from changes in the mean flow. This assumption was made in evaluating the proposed improvements to the Narrows.

\section{APPLICATION OF EQUATIONS TO BURRARD INLET}

Basic Equations - For each basin an equation of continuity similar to Eq. (I) can be written. It can be briefly stated: The rate of rise of a basin multiplied by the surface area is equal to the sum of the discharges into that basin. It is convenient to use in the nomenclature subscripts referring specifically to a given channel or bay. The subscripts 0,1 and 2 are used for English Bay, Vancouver Harbour and the Jpper Inlet respectively, $a$ and $b$ 
are used for reference to the First and Second Narrows respectively. With this nomenclature the continuity equations are:

$$
v_{b} a_{b}=A_{3} \frac{d h_{3}}{d t}
$$

and

$$
v_{a} a_{a}-v_{b} a_{b}=A_{2} \frac{d h_{2}}{d t}
$$

Upon combining these equations with dynamic equations for each channel identical to Eq. (3) there results the followil basic equations for the flow.

$$
\frac{d^{2} V_{a}}{d t^{2}}+\frac{f_{a}}{8 R_{a}} \frac{d}{d t}\left(V_{a}\left|V_{a}\right|\right)+\frac{g}{L_{a} A_{2}} V_{a}-\frac{g a_{b}}{L_{a} A_{2}} V_{b}=\frac{g}{L_{a}} \cdot \frac{d h_{0}}{d t}
$$

$$
\frac{d^{2} V_{b}}{d t^{2}}+\frac{f_{b}}{8 R_{b}} \frac{d}{d t}\left(V_{b}\left|V_{b}\right|\right)+\frac{g a_{b}}{L_{b}}\left(\frac{I}{A_{2}}+\frac{I}{A_{3}}\right) V_{b}-\frac{g a_{a}}{I_{b} A_{2}} V_{a}=0
$$

Tide Curve for English Bay - One essential boundary condition on Eqs. (II) and (I2) which must be specifled before proceeding further is the expression for $h_{0}$ which is given the apt title of the forcing function in applied mathematics. The simple cosine expression, Eq. (4) will be used to derive the linear solution of Eqs. (II) and (I2) although this is not a good representation of the natural tide curve (see Fig. 3). This curve, which is assumed to be the level variation measured at Caulfeild Cove, is typical of those encountered on the Pacific Coast. There are two high and two low tides every day, the relative heights of which vary from day to day. Maximum currents are found wher the greatest difference between high-high and low-low occurs The curve for Caulfeild Cove can be described by a series of cosine terms by either a Fourier representation in terms of a basic period and its harmonics or by a series of standard tidal periods. Each of these methods is a linear combination of cosine terms and hence the solution for such a forcing function can be obtained by the same Iinear combination of solutions for Eq. (4). In other words, solutions obtaine by using the simple cosine expression combine by superposition. This procedure greatly simplifies working with any observed curve.

Solution of Basic Equations - The simplified solution for two basins in series is identical to Eq. (5). In terms of the above nomenclature the velocities in the Narrows are: 


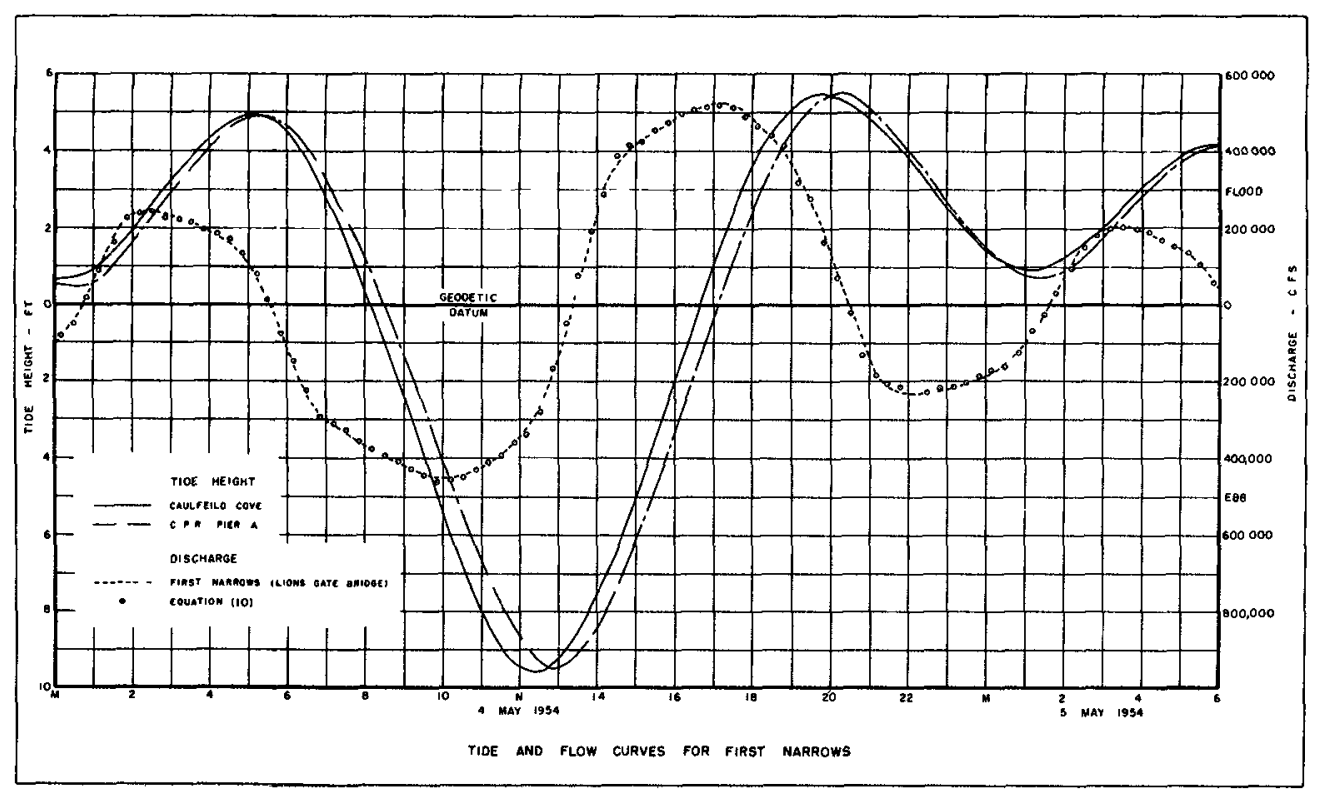

Fig. 3. Tide and flow curves for First Narrows .

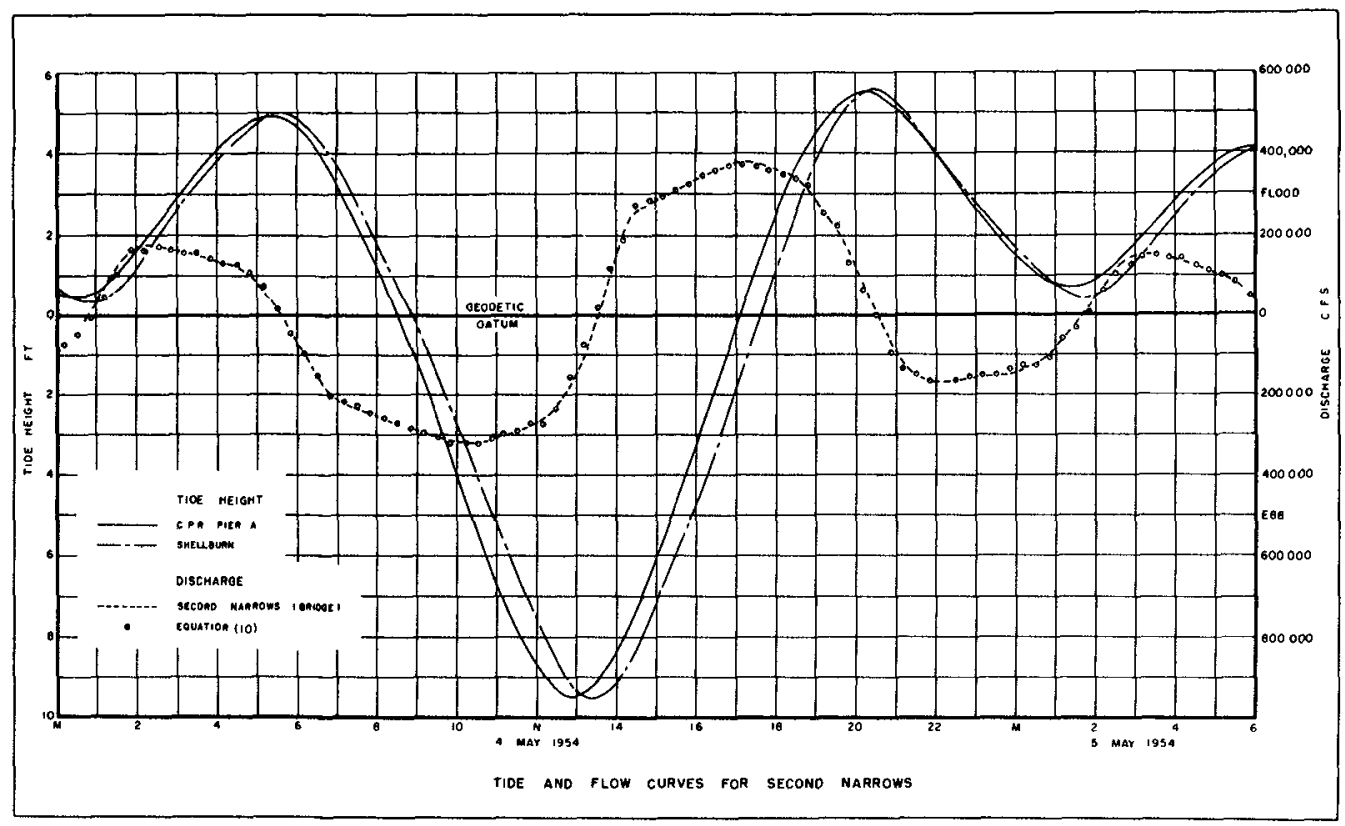

Fig. 4. Tide and flow curves for Second Narrows. 


$$
\begin{aligned}
& V_{a}=-\frac{2 \pi H}{T} \frac{A_{1}+A_{2}}{a_{a}} \sin \frac{2 \pi t}{T} \\
& V_{b}=-\frac{2 \pi H}{T} \frac{A_{2}}{a_{b}} \sin \frac{2 \pi t}{T}
\end{aligned}
$$

The linear solution is, however, much more complex than for the single basin. Using Laplace Transform methoc (ref. 3) the following expressions are obtained for velocities and tide curves:

$$
\begin{aligned}
& v_{a}=-\frac{c_{1}\left(c_{7}-1\right)}{\left(c_{3}-1\right)\left(c_{7}-1\right)\left[1-\tan \alpha_{3} \tan \alpha_{5}\right]-c_{4} c_{5}} x \\
& \frac{\cos \alpha_{2}}{\cos \alpha_{3}} \sin \left(\frac{2 \pi t}{T}-\left(\alpha_{2}-\alpha_{3}\right)\right) \\
& v_{b}=-\frac{c_{1} c_{5}}{\left(c_{3}-1\right)\left(c_{7}-1\right)\left[1-\tan \alpha_{3} \tan \alpha_{5}\right]-c_{4} c_{5}} x \\
& \cos \alpha_{2} \sin \left(\frac{2 \pi t}{T}-\alpha_{2}\right) \\
& \frac{h_{1}}{H}=\frac{c_{3}\left(c_{8}-1\right)}{\left(c_{3}-1\right)\left(c_{7}-1\right)\left[1-\tan \alpha_{3} \tan \alpha_{5}\right]-c_{4} c_{5}} x \\
& \frac{\cos \alpha_{2}}{\cos \alpha_{4}} \times \cos \left(\frac{2 \pi t}{T}-\left(\alpha_{2}-\alpha_{4}\right)\right) \\
& \frac{h_{2}}{H}=\frac{c_{3} c_{8}}{\left(c_{3}-1\right)\left(c_{7}-1\right)\left[1-\tan \alpha_{3} \tan \alpha_{5}\right]-c_{4} c_{5}} x \\
& \cos \alpha_{2} \times \cos \left(\frac{2 \pi t}{T}-\alpha_{2}\right)
\end{aligned}
$$


In which all of the constants $C$ are coefficients of equations (11) and (12), namely:

$$
\begin{aligned}
& C_{1}=\frac{T g H}{2 \pi L_{a}} ; \quad c_{2}=\frac{f_{b} T\left|V_{a}\right|}{2 \pi \times 8 R_{a}} ; \quad c_{3}=\frac{g T^{2} a_{a}}{4 \pi^{2} L_{a} A_{2}} ; \\
& C_{4}=\frac{g T^{2} a_{b}}{4 \pi^{2} L_{a} A_{2}} ; \quad c_{5}=\frac{g T^{2} a_{a}}{4 \pi^{2} L_{b} A_{2}} ; C_{6}=\frac{f_{b} T\left|V_{b}\right|}{2 \pi \times R_{b}} \\
& C_{7}=\frac{g T^{2} a_{b}}{4 \pi^{2} I_{b}}\left(\frac{1}{A_{2}}+\frac{1}{A_{3}}\right) ; \quad C_{8}=\frac{g T^{2} a_{b}}{4 \pi^{2} L_{b} A_{3}} ;
\end{aligned}
$$

and the angles defining phase shifts are defined by:

$\tan \alpha_{2}=\left(\tan \alpha_{5}+\tan \alpha_{3}\right) /\left[1-\tan \alpha_{5} \tan \alpha_{3}-\right.$

$$
\left.\frac{c_{4} c_{5}}{\left(c_{3}-1\right)\left(c_{7}-1\right)}\right]
$$

$\tan \alpha_{3}=\frac{C_{6}}{C_{7}-1}(20) ; \quad \tan \alpha_{4}=\frac{C_{6}}{C_{8}-1}(21)$;

$$
\tan \alpha_{5}=\frac{c_{2}}{c_{3}-1}
$$

Examination of these equations shows a rather unexpected relationship between the phases of the several tides and currents. There is a basic delay $\alpha_{2}$ between the tide in English Bay and that in the Upper Inlet. The tide in Vancouver Harbour precedes that in the Upper Inlet by $\alpha$ but there is not a simple expression for the phase difference between the tide in the Harbour and in English Bay. For the currents, that in the Second Narrows is exactly 90 degrees out of phase with the tide in the Upper Inlet, while that in the First Narrows has a different relationship to the tide in the Upper Inlet than all other of the variables. The current in the First Narrows is neither in phase with the tide in English Bay nor with that in Vancouver Harbour.

Verification of Mathematical Model - The only data of high enough quality for this verification are those obtained by the University of British Columbia staff in their tidal 
COASTAL ENGINEERING

Table I

Constants for Burrard Inlet

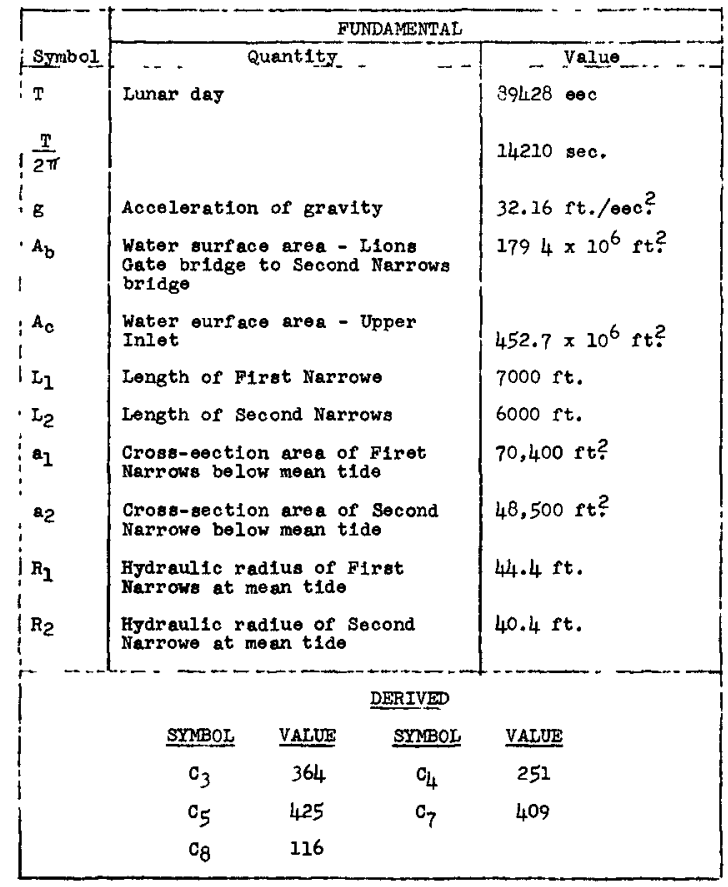

Table II

Constant associated with friction terms in linear solution.

\begin{tabular}{|c|c|c|c|c|c|c|c|}
\hline \multirow[b]{2}{*}{$\begin{array}{l}\text { Dete } \\
1954\end{array}$} & \multirow[b]{2}{*}{ Current } & \multicolumn{4}{|c|}{ AVERAGE PHASE SHIFT } & \multicolumn{2}{|c|}{ FRIOTION FACTOR } \\
\hline & & $\begin{array}{l}\frac{\mathrm{T}^{2}}{2 \pi} \\
\mathrm{hr} .\end{array}$ & $\begin{array}{l}\frac{T 2}{2 \pi} \\
h r .\end{array}$ & $\begin{array}{l}\frac{T \alpha_{4}}{2 \pi} \\
h r .\end{array}$ & $\begin{array}{l}\frac{T \alpha_{5}}{2 \pi} \\
h r .\end{array}$ & $e_{a}$ & $s_{b}$ \\
\hline \multirow[t]{4}{*}{4 May } & slow-Flood & 0.50 & 0.062 & 0.22 & 0.079 & 0.058 & 0.049 \\
\hline & Fast-Ebb & 1.17 & 0.155 & 0.55 & 0.189 & 0.049 & 0.046 \\
\hline & Fast-Flood & 1.00 & 0.147 & 0.52 & 0.141 & 0.045 & 0.044 \\
\hline & Slow-Ebb & 0.40 & 0.056 & 0.2 & 0.056 & 0.045 & 0.046 \\
\hline \multirow[t]{4}{*}{5 May } & Slow-Flood & 0.45 & 0.065 & 0.23 & 0.062 & 0.052 & 0.053 \\
\hline & Fast-Ebb & 1.18 & 0.155 & 0.55 & 0.192 & 0.050 & 0.046 \\
\hline & Fast-Flood & 1.02 & 0.155 & 0.55 & 0.141 & 0.044 & 0.051 \\
\hline & SIOW-Ebb & 0.40 & 0.059 & 0.21 & 0.054 & 0.045 & 0.049 \\
\hline \multirow[t]{2}{*}{6 May } & Slow-Flood & 0.40 & 0.056 & 0.2 & 0.056 & 0.047 & 0.053 \\
\hline & & & & & AVERAGE & 0.049 & 0.049 \\
\hline MOTE: & $\begin{array}{l}\text { quantit1 } \\
\text { Table I. }\end{array}$ & & & & cu & All & ar \\
\hline
\end{tabular}




\section{TIDAL ĊURRENTS IN CONSTRICTED INLETS}

survey (Ref. 4). Over the past 50 years there have been scattered measurements of tides and currents in the Inlet but these were not directly comparable because of the wide variation in the tide occurring at the seaward end. An accurate description of the tidal flow requires simultaneous measurement of the tide at a large number of locations covering all parts of the inlet together with check metering of the discharge. Such a survey was made from May 4 through May 6, 1954, and the information obtained therefrom has been accurately checked, correlated, and issued as Ref. (4). For the complete period which included two tide cycles the discharge in both Narrows was computed by the cubature method. Because the fresh water inflow is negligible the resulting figures are exact. Throughout this report this information will be used to evaluate the mathematical formulation.

The first step is to check the simplified continuity equation. With the surface area given in Table $I$ and the graphical solution for the slope of the tide curve the second Narrows discharge $Q_{b}$ was evaluated and is plotted on Figure 4. Considering the accuracy of a graphical solution the agreement is excellent. A similar computation was made for $Q_{a}$, the First Narrows discharge. The representative tide for Vancouver Harbour was chosen as that at Pier $A$. The resulting values are plotted on Figure 3 whereon it can be seen that the agreement is very good. The largest discrepancies between the approximate and exact values are of the order of two percent. Therefore it is shown that the continuity assumption is valid.

The complete solution is more difficult to verify because the constant, describing the friction effect, cannot be directly measured in the inlet. The best procedure appears to be the evaluation of the friction factor from the tide survey assuming that all of the geometrical factors are accurately determined. This too is difficult to perform directly. The reason is obvious when the equations for phase shift (which are expressions of the friction effect) are compared to the measured tide curves. As an example, consider the phase shift across the Second Narrows (see Fig. 4). The time difference between the two curves is expressed in the linear solution by the angle $\alpha 4$. It is readily shown that this angle is small enough that ${ }^{\text {its }}$ tangent is equal to the angle itself. Furthermore, in equation (2l) the constant $C_{8}=364$, hence an error of less than one percent is introduced by neglecting the factor one in the denominator with these assumptions and writing the phase shift time $\frac{T}{2 \pi} \alpha_{4}$ in place of the phase shift angle $\alpha_{4}$ the following equation results:

$$
\frac{T}{2 \pi} \alpha_{4}=\frac{f_{b}\left|v_{b}\right| I_{b}}{8 g} A_{3}
$$


The phase shift time is the quantity found directly by measuring the time difference between the curves on Figure 4 . Throughout the analysis it has been assumed that all terms the right-hand side of equation (23) were invariable with $t$ tide conditions. This means that the phase shift time is constant and the Shellburn curve should be displaced a constant amount from the Pier A curve. This, however, is not the case as is clearly shown on Table II wherein measured. values of $\frac{T}{2 \pi} \alpha_{4}$ are entered. There is actualis a varlati from $0.2 \mathrm{hr}$. to $0.55 \mathrm{hr}$. Such a result does not completely negate a linear solution if a slightly different interprete tion is now put on 1 t.

A more realistic approach is to divide the tide curr into different periods between the times of slack water. F definition these have been given the names of slow or fast, flood or ebb, to give the same sort of terminology applied the tide curve peaks, e.g., high-low tide. For each perioc all terms in equation (23) are assumed constant but the va] of $V_{b}$ is taken as the maximum occurring in this particule period and not that for the day. $P_{b}$ is assumed as the mes depth at the time $V_{b}$ is a maximum. Following this procec the friction factor $f_{b}$ has been evaluated and is entered the last column in Table II. There is a spread of roughly percent in the values compared to 150 percent in the phase shift time. This result is extremely good when it is real: that a phase shift is difficult to determine from the curve to an accuracy better than 10 percent. It would not be sus prising if $f_{b}$ were different for $\theta b b$ and flood flows. Tr different geometry as the flow reversed should give differe entrance and exit losses. No consistent varlation shows if the results so it is assumed that the same value holds for each case. Probably a difference does exist but it is sma: than the scatter of the results.

For the First Narrows a simplified equation similar to equation (23) cannot be written. However, an analysis similar to that described above can be made starting with. phase shift between Caulfeild and shellburn $\frac{T}{2 \pi} \alpha_{2}$. This quantity has the same extreme variations as $\frac{T}{2 \pi} \alpha_{4}$. Next equations (20) and (19) are solved in succession to yield results for $\frac{T}{2 \pi} \alpha_{3}$ and $\frac{T}{2 \pi} \alpha_{5}$ other phase shift times of significance. Finally, $f_{a}$ is derived from equation (22) $\alpha_{5}$ (see Table II). Again it is noted that the spread of values is much less than might be expected. A chance resu is the average value of $f$ for each narrows being 0.049 . This is not significant. Because of the very close agreem 
of friction factor throughout the tidal cycles it appears that the above procedure is the best method of interpreting the linear solution.

A further confimation of this procedure is the prediction of phase for the flow curves for the First and Second Narrows. Figures 5 and 6 are plots of the linear and simplified solutions for $Q_{a}$ and $Q_{b}$ along with curves resulting from the tide survey. From this it is seen that the Iinear solution (using the phase shift times found in Table II) is in very close agreement on the time base with the exact curve. Such is taken as further proof of the accuracy of the adopted procedure because the curves on Figures 5 and 6 depend entirely on values measured from the tide curves. The simplified solution, on the other hand, is seriously in error because it does not contain an expression for phase shift but assumes that events throughtout the Inlet occur at the same instant.

\section{EHFECTS OF CHANNEL IMPROVEMENTS}

The primary reason for developing the above mathematical model and performing the lengthy observations and analysis on Burrard Inlet was the need to evaluate proposals for improving the navigation channels through the Narrows. The existing channels are too narrow and shallow for the vessels anticipated in the very near future. The major improvement is a proposed removal of about 8 million cubic jards of material from the north side of the First Narrows. This would double the width of the navigation channel at 40 feet below low water. In addition the sharp turn required of vessels entering the Narrows would be considerably reduced. The design of this enlargement was dictated by navigation requirements and not hydraulic considerations. Because of the resulting change in channel configuration it was concluded that the mathematical formulation would not accurately predict the maximum current or direction. Consequently it was decided to construct a hydraulic model of the First Narrows which could be run in a steady state at maximum flood and ebb flows. This model was built and operated by the Department of Civil Engineering of the University of British Columbia, under the supervision of Prof. E. S. Pretious. The horizontal scale was $1: 400$ and the vertical scale $1: 100$. Data from the tidal survey of the Inlet was used in the verification and the above mathematical development used to predict the discharge required after the dredging programme was completed. Model results were entirely satisfactory and showed that the enlargement would improve the hydraulic characteristics much more than the mathematical solution indicated. In evaluating the influence of this enlargement on currents in the second Narrows the model results were used to define a new friction factor for the First Narrows. This 


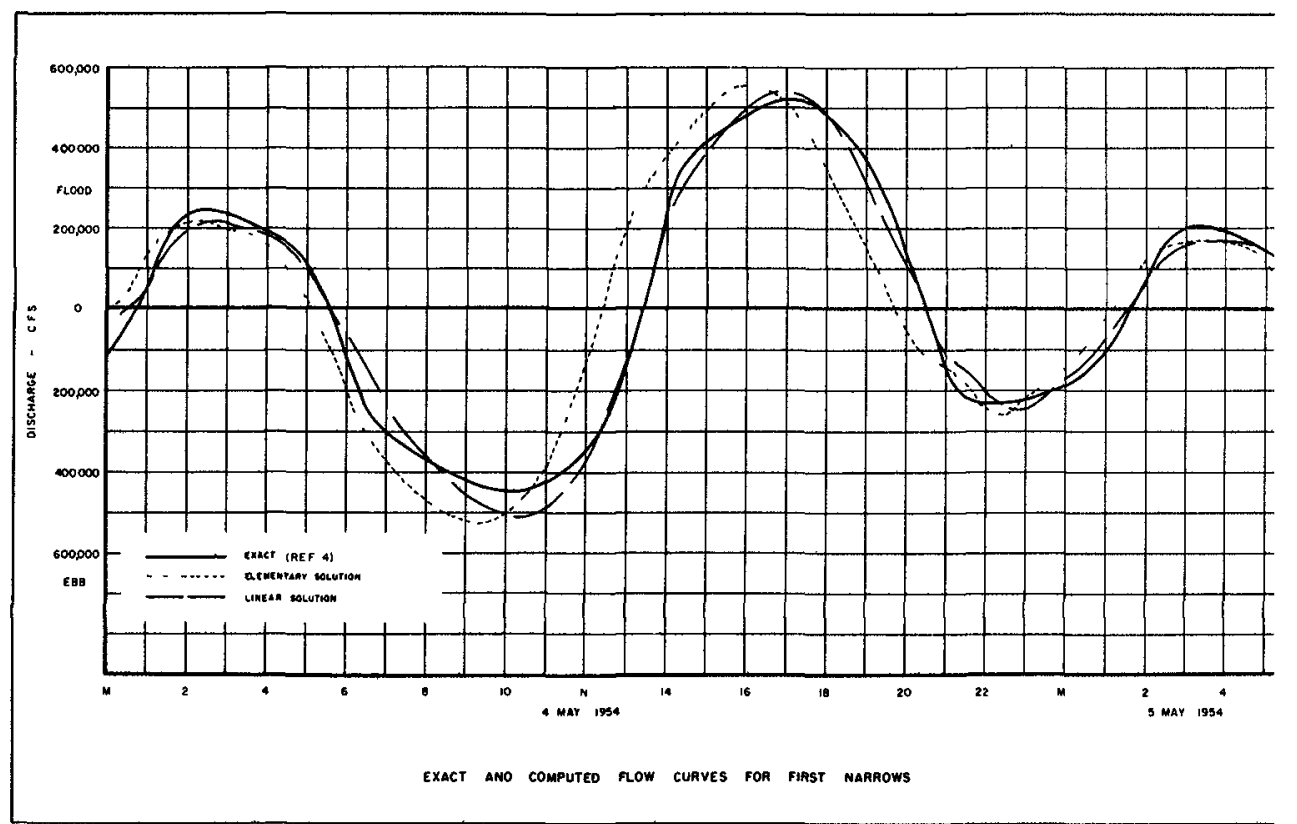

Fig. 5. Exact and computed flow curves for First Narrows.

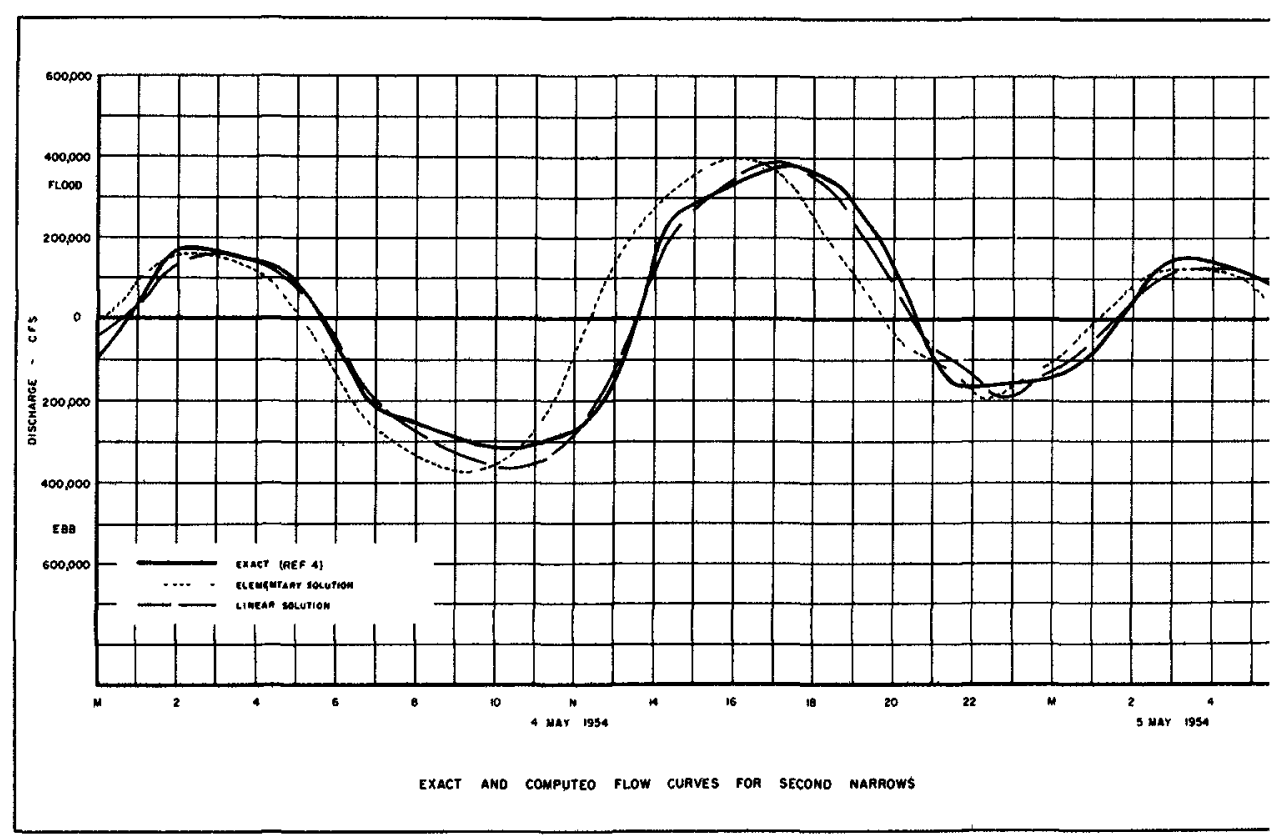

Fig. 6. Exact and computed flow curves for Second Narrows. 


\section{TIDAL CURRENTS IN CONSTRICTED INLETS}

was inserted in equations (16) and (18) and it was found that the discharge and velocity in the Second Narrows would increase by about $1 \%$. Other predictions were made regarding the phase differences in the tide curves but these have no practical significance. It is hoped to check this analysis by further measurements in the Inlet when the enlargement is completed.

As part of this study other possible improvements to the harbour were also evaluated. The mathematical solution was used exclusively but it was recognized that the results would not be so accurate without hydraulic model studies. Various schemes for widening and deepening the Second Narrows were considered. It was found that in every case the velocities in this channel were reduced with the accompanying increase of velocities in the remainder of the Inlet being less than $1 \%$.

The most spectacular reduction in currents would be obtained by closing the Second Narrows. Effectively this removes over $70 \%$ of the tidal volume of the Inlet and so the discharge and velocities in the First Narrows would be reduced to about $30 \%$ of the values now existing.

\section{CONCLUSION}

A mathematical formulation for flow in a tidal basin with a constricted inlet has been developed. When applied to Burrard Inlet it has been found that the formulation gives an accurate description of the mean velocity and tide levels in all locations.

\section{REFERENCES}

1. Caldwell, J.M., Tidal Currents at Inlets in the United States, Proc. ASCE, vol. 81, Separate No. 716, June 1955.

2. Einstein, H.A., Computation of Tides and Tidal Currents - United States Practice, Proc. ASCE, vol. 81, Separate No. 715, June 1955.

3. Churchill, R.V., Modern Operational Mathematics in Engineering, McGraw-Hill Book Co., New York, 1944.

4. Cox, I., Burrard Inlet Tidal Survey, Dept. of C1vil Fingineering, Univ. of British Columbia, Nov. 1954. (Unpublished report).

5. Anon., Tidal Current Charts, Vancouver Harbour, B.C., Tidal Publication No. 22, Tidal and Current Survey, Canadian Hydrographic Survey, Dept. of Mines and Technical Surveys, Ottawa, Feb. 1952. 